
@०

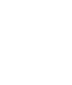

\title{
Heavy precipitation events in the Mediterranean: sensitivity to cloud physics parameterisation uncertainties
}

\author{
S. Fresnay ${ }^{1}$, A. Hally ${ }^{1}$, C. Garnaud ${ }^{1, *}$, E. Richard ${ }^{1}$, and D. Lambert ${ }^{1}$ \\ ${ }^{1}$ Laboratoire d'Aérologie, UMR5560, CNRS and Université de Toulouse, Toulouse, France \\ * currently at: ESCER Center, Université du Québec à Montréal, Montréal, Canada
}

Correspondence to: S. Fresnay (simon.fresnay@aero.obs-mip.fr)

Received: 28 January 2012 - Revised: 18 June 2012 - Accepted: 29 June 2012 - Published: 24 August 2012

\begin{abstract}
In autumn, southeastern France is often affected by heavy precipitation events which may result in damaging flash-floods. The 20 October and 1 November 2008 are two archetypes of the meteorological situations under which these events occur: an upper-level trough directing a warm and moist flow from the Mediterranean towards the Cévennes ridge or a quasi stationary meso-scale convective complex developing over the Rhone valley. These two types of events exhibit a contrasting level of predictability; the former being usually better forecast than the latter. Control experiments performed with the Meso-NH model run with a $2.5 \mathrm{~km}$ resolution confirm these predictability issues. The deterministic forecast of the November case (Cévennes ridge) is found to be much more skilful than the one for the October case (Rhone valley). These two contrasting situations are used to investigate the sensitivity of the model for cloud physics parameterisation uncertainties. Three 9-member ensembles are constructed. In the first one, the rain distribution intercept parameter is varied within its range of allowed values. In the second one, random perturbations are applied to the rain evaporation rate, whereas in the third one, random perturbations are simultaneously applied to the cloud autoconversion, rain accretion, and rain evaporation rates. Results are assessed by comparing the time and space distribution of the observed and forecasted precipitation. For the Rhone valley case, it is shown that not one of the ensembles is able to drastically improve the skill of the forecast. Taylor diagrams indicate that the microphysical perturbations are more efficient in modulating the rainfall intensities than in altering their localization. Among the three ensembles, the multi-process perturbation ensemble is found to yield the largest spread for most parameters. In contrast, the results of the Cévennes case exhibit almost no sensitivity to
\end{abstract}

the microphysical perturbations. These results clearly show that the usefulness of an ensemble prediction system based upon microphysical perturbations is case dependent. Additional experiments indicate a greater potential for the multiprocess ensemble when the model resolution is increased to $500 \mathrm{~m}$.

\section{Introduction}

The Mediterranean basin is a region prone to high rainfall and stormy events causing severe damage and human losses almost every year. These high-impact meteorological events need to be accurately forecasted, justifying important cooperative research efforts, such as the WMO World Weather Research Programme MEDiterranean EXperiment (MEDEX, http://medex.aemet.uib.es/) or the forth-coming HYdrological cycle in Mediterranean EXperiment (HyMeX, http://www.hymex.org/). The former is dedicated to the study of high-impact cyclones over the Mediterranean, whereas the latter aims at a better understanding and forecasting of the whole water cycle in the Mediterranean. In particular, the first HyMeX Special Observing Period (SOP), scheduled for autumn 2012, will specifically focus on heavy precipitation events in the northwestern Mediterranean and will provide a unique opportunity to implement and assess new forecasting methodologies aiming to improve the predictability of these events.

In southeastern France, climatology exhibits a peak of high precipitation events in October with more than 90 high rainfall days - daily rainfalls greater than $150 \mathrm{~mm}$ - registered for the 1967-2006 period. These events mainly occur over the Cévennes range (see Fig. 1 for geographical

Published by Copernicus Publications on behalf of the European Geosciences Union. 


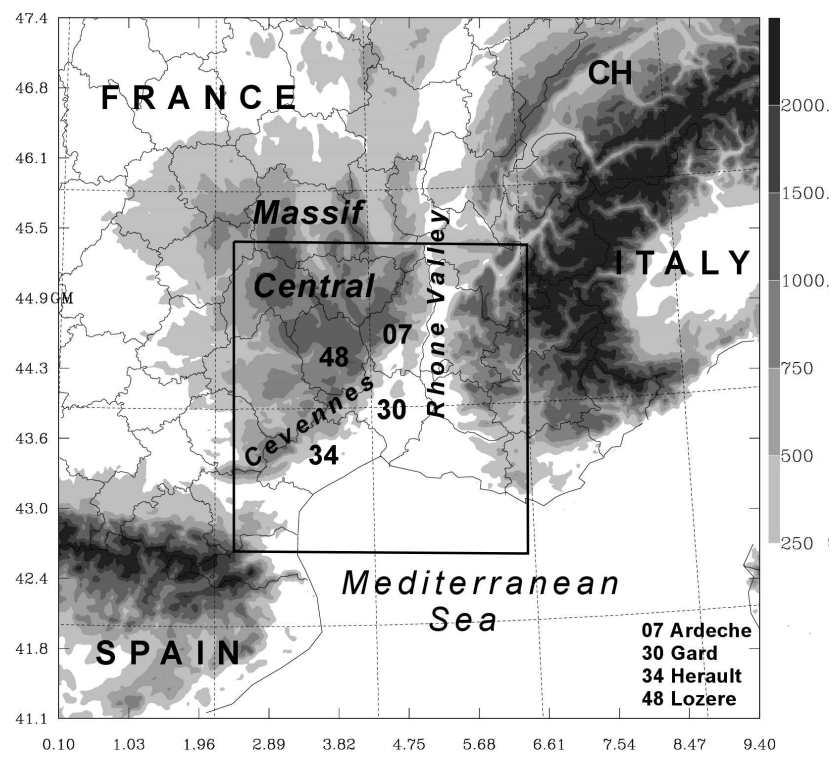

Fig. 1. Map of the domain of Southern France used for the simulations, with a $2.5-\mathrm{km}$ resolution. Solid line indicates box where statistics have been performed, that is the Languedoc and Southern Massif Central area. Shading represents altitudes (in meters) over $250 \mathrm{~m}$. Geographical names and French administrative regions are recalled, in particular 4 departements of the Languedoc area with their standard number.

locations) but also hit the highly-populated plains close by, posing a serious threat to the population and to economic activities. Catastrophic floods, such as the 1999 Aude case or the 2002 Gard case, deserved several studies (e.g. Bechtold et al., 2001, Nuissier et al., 2008, Ducrocq et al., 2008) helping to identify the main factors responsible for the severity of these events. In particular, the stationarity and location of the mesoscale convective system (MCS) for the Gard case were shown to be very sensitive to evaporation processes and resulting cold pool developments. The presence of a cold pool was also suspected for an unusually high precipitation event on the eastern shore of Corsica (Lambert and Argence, 2008).

Despite all the progress in numerical weather prediction, predictability of these events, which involve intricate multi-scale processes, remains fairly limited. The theoretical framework of predictability was pioneered by Lorenz (1963), who studied the propagation of small initial errors through simple atmospheric models. Later on, Lorenz (1969) estimated the theoretical predictability limit to be a few weeks for large-scale flows but to be only an hour for cumulus scale motions. More recently, in a paper summarising critical points of convection predictability in the US, Fritsch and Carbone (2004) made the general observation that skilful deterministic prediction of deep convection and associated rainfall is still limited to a few hours only. Moreover, several studies (e.g. Walser, 2004) have shown how moist instability was capable of disrupting predictability even at the synoptic scale.
To overcome this current limitation, ensemble prediction is a promising strategy. From a set of perturbed scenarios, which model the uncertainties of the initial atmospheric state, ensemble prediction gives a probabilistic picture of the likelihood of the phenomena. The main difficulty associated with this strategy is to design appropriate and realistic perturbations to get enough dispersion of the scenarios and significant statistical scores. At the global and synoptic scales, ensemble prediction systems are based on well-proved methodologies but much less knowledge exists for the convective scale. Hohenegger and Schär (2007) investigated how different mesoscale errors propagate through a cloud-resolving model. It appears that within a dozen hours, various perturbations, even randomly distributed, lead to a maximum spread over regions where moist convection takes place. This is an indication that precise meso-scale perturbations could only be valuable for a very short forecasting range, whereas random perturbations might induce similar spread for more extended forecasts. Furthermore, from these results, which clearly underline the role of the convective processes, it could be hypothesised that the microphysical cloud scheme uncertainties also play a major role in the error propagation and therefore should also be taken into account in a convectivescale ensemble prediction system.

Past studies have addressed the issue of physical parameterisation uncertainties. They are cast into two categories involving either the use of different physical parameterisation schemes (e.g. Houtekamer et al., 1996; Stensrud et al., 2000) or stochastic physical parameterisations (e.g. Buizza et al., 1999b; Palmer, 2001; Grell and Dévényi, 2002). In the first category, model uncertainties are accounted for by using various combinations of different boundary layers, microphysics, and land surface schemes. To be valuable, such an ensemble requires the availability of a wide range of parameterisations within the model. In the second category, stochastic physics aim at representing model uncertainty that results from interactions with unresolved scales. Therefore, this approach was mainly used at large scales to compensate for deficiencies in turbulence and deep convection parameterisations.

Our goal in this study is to explore the importance of model uncertainties associated with the cloud representation at the convective scale. Two cases of high precipitation over southern France, exhibiting very different levels of predictability, are considered. The sensitivity of the precipitation forecast to the details of the cloud physics parameterisation is assessed by (i) varying the tuneable parameters of the microphysical scheme of the model within their range of allowed values and (ii) introducing random perturbations on the time tendencies of the microphysical processes. The first methodology can be seen as a "poor man's" version of the multi-scheme approach, whereas the second one can be considered as an extension of the stochastic physics approach towards the convective scale. The results obtained with the two types of microphysical perturbations are then compared 
to those obtained with initial condition perturbations. Finally, the sensitivity of the results to model resolution is examined.

The paper is organised as follows. Section 2 gives an overview of the studied cases and describes the numerical model and the perturbation setup. The sensitivity of the precipitation fields to the microphysical perturbations is analysed in Sect. 3. The results of the additional experiments are discussed in Sect. 4. Conclusions and outlook are given in Sect. 5.

\section{Cases studied and model settings}

\subsection{Cases studied}

The events studied occurred in 2008 over southern France from the Gard and Hérault plains to the Cévennes mountains (see Fig. 1). This region is well known for its exposure to intense precipitation during the fall season, and will be one of the main observational sites during the 2012 HyMeX SOP.

The first episode took place on the 20 October 2008, resulting in a $164 \mathrm{~mm}$ rainfall maximum between 00:00 UTC on the 20 October and 00:00 UTC on the 21 October. An overview of the meteorological situation is given in Fig. 2. Synoptic analysis at mid level (Fig. 2a) shows a weak westerly flow and the domination of high geopotential heights over southeastern France. As seen on the vertical velocity field, no significant upper-level forcing affects the studied area. The $925 \mathrm{hPa}$ analysis (Fig. 2b) does not show any low-level cyclone in the surroundings but indicates southerly moist advection pointing toward the French coastlines. According to Nuissier et al. (2011), this situation does not appear propitious for a classical heavy precipitation event but low-level conditions are compatible with the occurrence of precipitation over this region. Figure $2 \mathrm{c}$ maps the observed 24-h rainfall. The highest rainfall was fairly localized and observed over the plain regions of Hérault and the Gard, whereas accumulated precipitation over the southeastern Massif Central and western Alps remained relatively weak. Satellite (not shown) and radar data (e.g. Fig. 2d representative of the peak of the event) indicate that the intense precipitation was produced by a quasi-stationary linear MCS with parallel stratiform precipitation according to the taxonomy of Parker and Johnson (2000). Finally, Fig. 2e and $\mathrm{f}$ show the time evolution of the closest sounding located in Nîmes. On the 20 October between 00:00 UTC and 12:00 UTC, the atmosphere was destabilised by cold air advection in the upper levels. The convective available potential energy (CAPE) increased from 0 to $183 \mathrm{~J} \mathrm{~kg}^{-1}$, whereas the lifted index (LI) evolved from 3.3 to $-0.9 \mathrm{~K}$. Although the atmospheric vertical structure became favorable for convective developments, the instability remained fairly moderate. Former studies (Ardilouze, 2009) of this case have underlined the presence of a long-lived cold pool upstream of the relief, suggesting a mechanism very similar to the Gard case studied by Nuissier et al. (2008) during which the blocking of the cold pool was favoured by the narrowing of the Rhone valley, and acted to force stationary updraughts upstream of the relief.

The second episode took place at the beginning of November, resulting in a $365 \mathrm{~mm}$ 24-h rainfall maximum between the 1 November 2008 at 12:00 UTC and the 2 November 2008 at 12:00 UTC over the Lozère department. Figure 3 provides an overview of the situation. The synoptic analysis (Fig. 3a and b) shows a strong south-south-westerly flow associated with an intense low-level cyclonic circulation over the western Iberian peninsula, causing deflection of surface winds towards the southeast. The upper-level forcing is much stronger than in the previous case and makes the Cévennes area very exposed to deep convection. Such a pattern clearly belongs to the so-called WL-HPE synoptic class identified in Nuissier et al. (2011) and recognised as one of the most favourable atmospheric situations for high precipitation over southern France. The 24-h rainfall observations (Fig. 3c) show that the highest rainfall was found along a specific axis, corresponding roughly with the Cévennes crest line. In contrast, precipitation over the plain region was rather limited. This feature is likely to be explained by the prominent role of the topography in controlling the location and intensity of the precipitation. The radar observations on the 2 November 00:00 UTC (i.e. at the event peak, Fig. 3d) reveal a narrow, south-north oriented convective line that takes birth off-shore. The Nîmes soundings (Fig. 3e and f) from 1 November at 12:00 UTC and 2 November at 00:00 UTC exhibit a deep unstable layer and significant values of CAPE $\left(811 \mathrm{~J} \mathrm{~kg}^{-1}\right.$ on the 1 November). The lifted index (evolving from 0.58 to $-0.74 \mathrm{~K}$ ) indicates that convective developments will require strong lifting but this is likely to occur owing to the strong upper-level forcing shown in Fig. 3a.

These two events highlight two contrasted ways of forcing strong and stationary updraughts and consequently producing high precipitation. One way to produce this heavy precipitation is to direct low-level moist air towards mountain slopes. It is common to use the Froude number $(\mathrm{Fr}=$ $U / \sqrt{N h}$ where $U$ is the horizontal velocity, $N$ the Brunt Vaissala frequency and $h$ the height of the topography) to assess whether the impinging flow will be either deflected around or forced to rise above the topography. This theory does not account for moist convection and details of topography and therefore may not be entirely relevant (e.g. Miglietta and Rotunno, 2005, 2009) but it emphasises that strong and weakly-stable low-level flows will tend to rise upon a modest crest line instead of being deflected. In Southern France, rapid flows impinging the Cévennes ridge yield the so-called "cevenol episodes", causing widespread and lasting precipitation. An alternative way of producing strong and stationary precipitation is to develop a long-lived slowly-propagating convective system. Such convective systems cause localised and very intense precipitation, and are able to develop away from the relief. Although the present work is based on two 

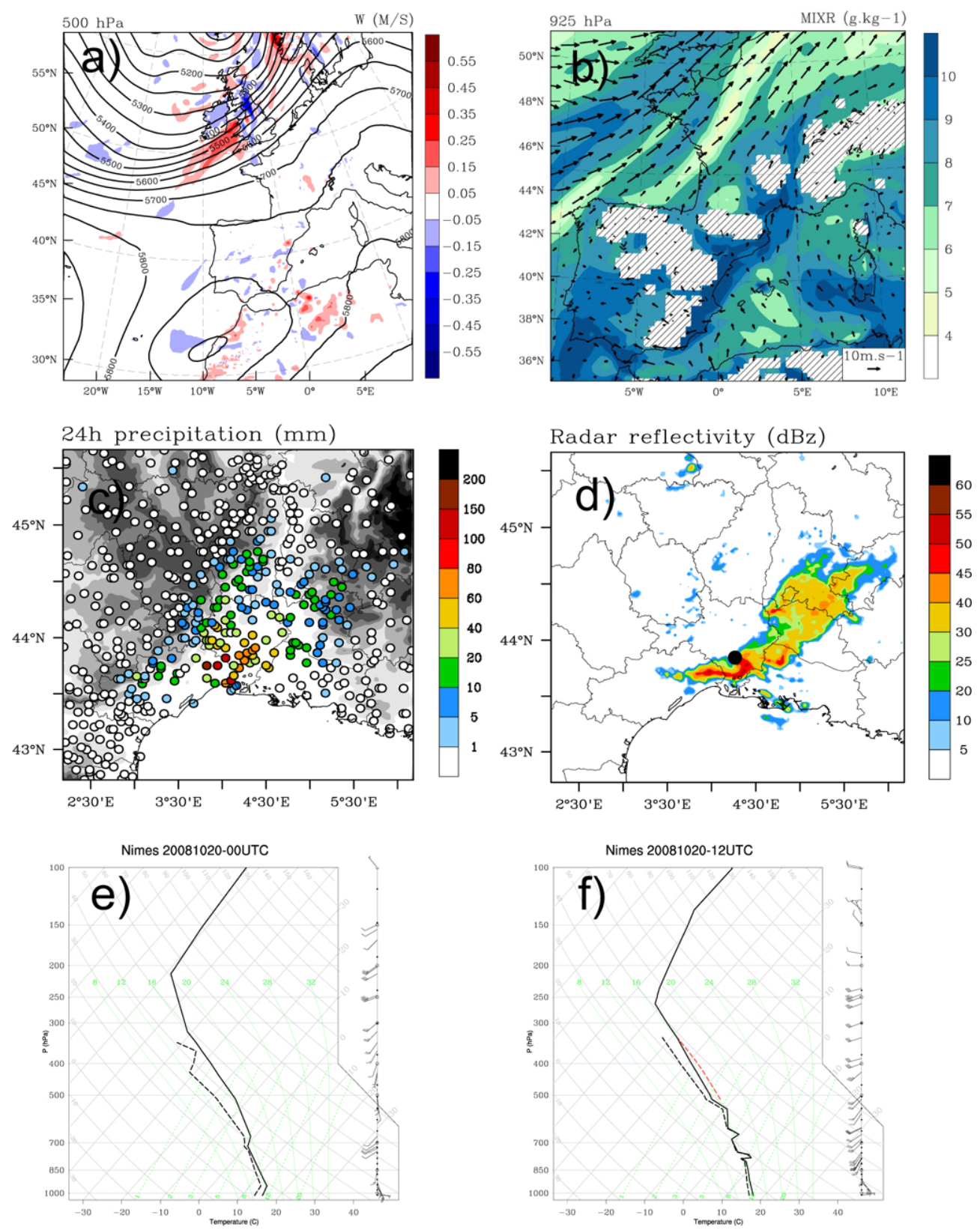

Fig. 2. Overview of the Gard-Hérault case. ECMWF analysis on 12:00 UTC, 20 October 2008: (a) $500 \mathrm{hPa}^{\text {vertical velocity (m s}} \mathrm{s}^{-1}$ ) and geopotential height (in $\mathrm{m}$ ) and (b) $925 \mathrm{hPa}$ water vapour mixing ratio and wind. (c) 24-h accumulated rainfall between 00:00 UTC, 20 October and 00:00 UTC, 21 October (Météo-France rain gauge network) with relief in shading. (d) Radar reflectivity (dBz) from the Nîmes radar (location indicated with the black dot) on 20 October 2008 at 15:00 UTC. (e and f) Nîmes soundings from 20 Ocober 2008 at 00:00 UTC and 12:00 UTC, respectively.

case studies only, it combines the two classical archetypes of these events which affect the area. However, it must be noted that the two types of events can combine, as orographic precipitation is often associated to embedded moist convection. In the following, the 1 November case will be referred to as the Cévennes case, whereas the 20 October case will be referred to as the Gard-Hérault case.

\subsection{Model}

The numerical experiments were conducted with the French research model Meso-NH (Meso-resolution NonHydrostatic model; Lafore et al. 1998). In order to focus on domain-internal errors, initial and boundary conditions were taken from the French high-resolution AROME operational 

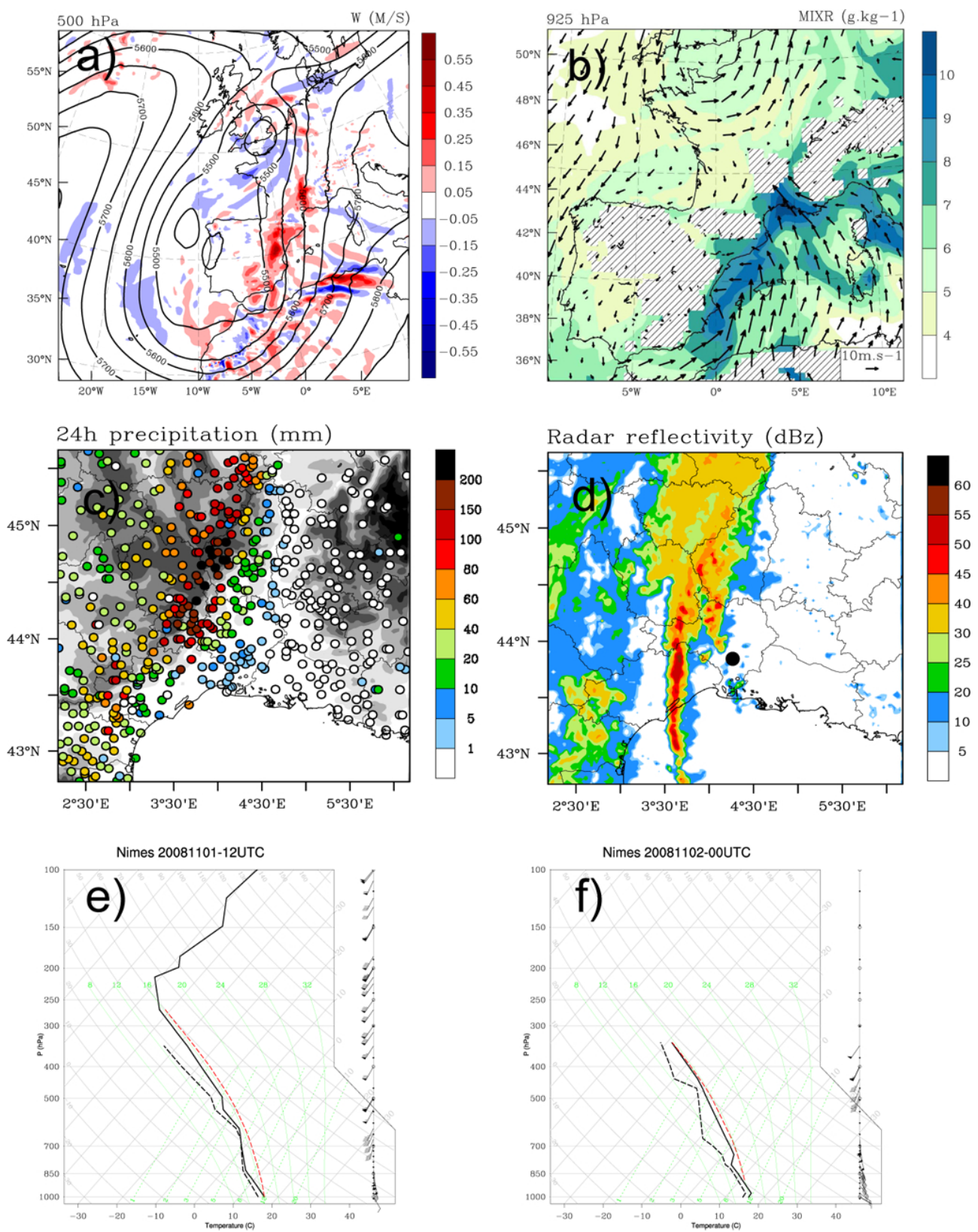

Fig. 3. Overview of the Cévennes case. ECMWF analysis on 00:00 UTC, 2 November 2008: (a) 500 hPa vertical velocity (m s$^{-1}$ ) and geopotential height (in m) and (b) $925 \mathrm{hPa}$ water vapour mixing ratio and wind. (c) 24-h accumulated rainfall between 12:00 UTC, 1 November and 12:00 UTC, 2 November (Météo-France rain gauge network) with relief in shading. (d) Radar reflectivity (dBz) from the Nîmes radar on 2 November 2008 at 00:00 UTC. (e and f) Nîmes soundings from 1 November 2008 at 12:00 UTC and 2 November 2008 at 00:00 UTC, respectively.

analyses (Seity et al., 2011) available every $3 \mathrm{~h}$ with a $2.5 \mathrm{~km}$ resolution.

Meso-NH is a grid point model which contains a full set of physical parameterisations. The turbulence scheme follows Cuxart et al. (2000) and the radiation is computed with the rapid radiative transfer model (Mlawer et al., 1997). The surface energy exchanges are represented according to four possible surface type patches (natural surfaces, urban areas, oceans, lakes) included in a grid mesh. The Interactions Soil-Biosphere-Atmosphere scheme (Noilhan and Mahfouf, 1996) is used for natural land surfaces. Deep and shallow convection are parameterised according to Bechtold et al. (2001) and Pergaud et al. (2009), respectively. The ICE3 bulk microphysical scheme (Pinty and Jabouille, 1998) governs the prognostic equations of six water species (vapour, cloud water, rainwater, primary ice, snow aggregates, and graupel). 
Table 1. Characteristics of the different ensembles

\begin{tabular}{llrl}
\hline $\begin{array}{l}\text { Ensemble } \\
\text { name }\end{array}$ & $\begin{array}{l}\text { Initial } \\
\text { conditions }\end{array}$ & $\begin{array}{r}\text { Horizontal } \\
\text { resolution }\end{array}$ & $\begin{array}{l}\text { Type of } \\
\text { perturbation }\end{array}$ \\
\hline E1 & 20 Oct 2008, 00:00 UTC & $2.5 \mathrm{~km}$ & Rain intercept parameter \\
E2 & 20 Oct 2008, 00:00 UTC & $2.5 \mathrm{~km}$ & Rain evaporation \\
E3 & 20 Oct 2008, 00:00 UTC & $2.5 \mathrm{~km}$ & Rain evaporation, autoconversion, accretion \\
E4 & 1 Nov 2008, 12:00 UTC & $2.5 \mathrm{~km}$ & Rain evaporation, autoconversion, accretion \\
E5 & 20 Oct 2008, 00:00 UTC & $2.5 \mathrm{~km}$ & Initial conditions \\
E6 & 20 Oct 2008, 06:00 UTC & $2.5 \mathrm{~km}$ & Rain evaporation, autoconversion, accretion \\
E7 & 20 Oct 2008, 06:00 UTC & $0.5 \mathrm{~km}$ & Rain evaporation, autoconversion, accretion \\
\hline
\end{tabular}

Compared to AROME, Meso-NH is more flexible regarding its setting, which in particular allows refined resolution in one or several sub-domains thanks to a two-way grid nesting technique (Stein et al., 2000).

The vertical grid was set to 50 levels (16 of them located in the first kilometre above ground) and was designed to get a close match in the low levels with the AROME vertical grid (which included only 41 levels in the 2008 operational version). The horizontal grid exactly matched the $2.5 \mathrm{~km}$ AROME grid and covered an AROME sub-domain centered over southeastern France (see Fig. 1). Considering the kilometre-order resolution of the simulations, the deep convection scheme was disabled but the shallow convection scheme was left on.

For the Gard-Hérault case, the simulations started at 00:00 UTC or 06:00 UTC on the 20 October and were conducted over $24 \mathrm{~h}$ or $18 \mathrm{~h}$. For the Cévennes case, they started at 12:00 UTC on the 1 November and were conducted over $24 \mathrm{~h}$.

\subsection{Configuration of microphysical perturbations}

The perturbation setup is derived from the previous study of Garnaud (2009). In this preliminary work, Garnaud studied the sensitivity of the model results to the details of the ICE3 microphysical scheme. Two different methodologies were explored from a series of academic tests ranging from isolated storms to organised squall lines. The first methodology aimed at assessing the sensitivity of the precipitation forecasts to tuneable parameters of the microphysical scheme, such as the hydrometeor distribution (e.g. the shape and intercept of the distribution), the hydrometeor mass-diameter and fall velocity-diameter relationships, and the various coefficients used in the computation of the microphysical processes (e.g. thresholds, time constants). All of these parameters were independently and systematically varied within their range of allowed values. The largest sensitivity was obtained for variations of the rain distribution intercept parameter and to a lesser extent for the snow distribution intercept parameter and the type of graupel. In the present study, only the perturbations expected to yield the largest sensitivity (i.e. the perturbations applied to the intercept parameter $N_{\text {or }}$ of the Marshall-Palmer distribution used to describe the raindrop spectrum) were retained. In the model standard configuration, $N_{\text {or }}$ is equal to $0.8 \times 10^{7} \mathrm{~m}^{-4}$, whereas according to literature, the admitted range of possible values extends from $0.4 \times 10^{7} \mathrm{~m}^{-4}$ to $3.6 \times 10^{7} \mathrm{~m}^{-4}$. The first set of experiments (E1) uses different values of $N_{\text {or }}$, regularly sampling the interval noted above with a $0.4 \times 10^{7} \mathrm{~m}^{-4}$ spacing. The E1 ensemble includes 9 members.

The second methodology used in Garnaud (2009) was inspired by Buizza et al. (1999b) and aimed at representing the random error associated with parameterised microphysical processes. This was achieved by introducing random perturbations on the time tendencies of each microphysical process. More specifically each time tendency was multiplied by a random factor homogeneous in time and space, ranging from 0.5 to 1.5 , and thus leading to an artificial increase or decrease in the considered process. The results obtained for the academic tests indicated that the largest sensitivity was obtained for perturbations applied to the rain evaporation process (which has a direct feedback on the model dynamics via evaporative cooling), and to a lesser extent to the accretion of cloud droplets by raindrops and to the autoconversion of cloud droplets into raindrops. In contrast, perturbations applied to the other processes (including riming, melting, ice accretion) induced a much smaller spread in the results. Furthermore, the sensitivity of the results was significantly increased when the perturbations were combined and simultaneously applied to the three warm processes mentioned above. For this study, the second set of experiments (E2) is based on the perturbations of the rain evaporation only (due to the suspected key role of the evaporative processes), whereas the third one (E3) considers combined perturbations on each of the warm processes. Each ensemble has 9 members, a reference simulation and 8 perturbed simulations. Table 1 provides the list of the experiments.

In contrast to Buizza et al. (1999b), in which perturbations were applied to subgrid-scale processes, the present perturbations operate on explicitly-resolved processes. However, it should be recalled that most of these supposedly explicit parameterisations do include unresolved processes. The autoconversion rate in a Kessler type formulation, which accounts for the initial coalescence of cloud droplets to form 

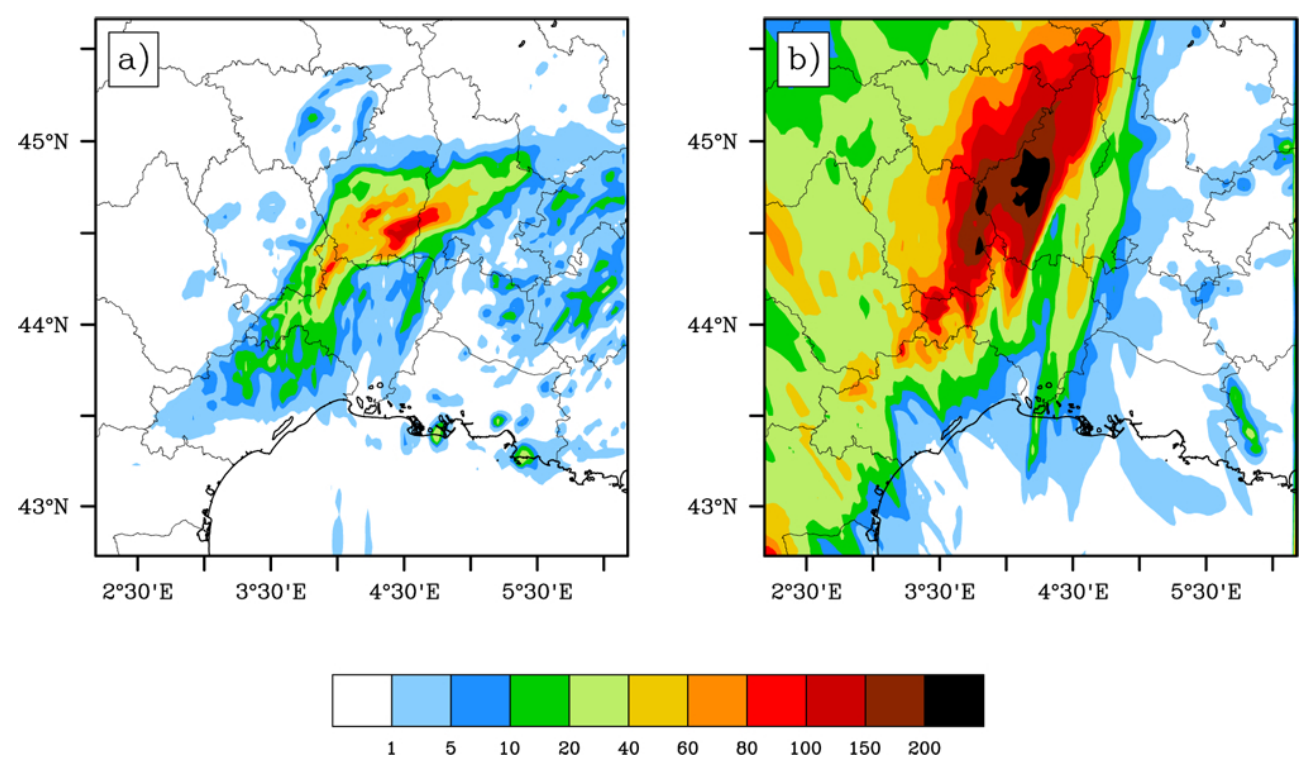

Fig. 4. $24 \mathrm{~h}$ accumulated precipitation (in $\mathrm{mm}$ ) from the reference simulations of the Gard-Hérault case from 20 October at 00:00 UTC to 21 October at 00:00 UTC (a) and for the Cévennes case from 1 November at 12:00 UTC to 2 November at 12:00 UTC (b).

raindrops, is expressed as proportional to the cloud water content only, and does not take into account the cloud droplet spectrum. To express efficiency of the accretion process between two drops having specific fall speed, coefficients obtained from experimental works are used and these need to be more accurately defined when flows are turbulent. The evaporation rate, finally, includes a ventilation coefficient depending strongly on the Reynolds number, which again questions the turbulent effects. Some studies addressed the problem (e.g. Franklin, 2008) and there is evidence that turbulent effects cannot be neglected. Moreover, initial uncertainties on raindrop size distribution will affect all rate calculations. Hence, by multiplying the computed rates with various constants, it is considered (as in Buizza et al.) that subgrid process parameterisations are not accurate enough to yield a correct representation of grid scale processes and budgets. It should be noted that mass conservation is still respected since the source and sink of the same process are enhanced or decreased by the same factor.

\section{Results}

\subsection{Reference experiments}

The simulated 24-h rainfall of the two control experiments is presented in Figs. 4a and b for the Gard-Hérault case and Cévennes case, respectively. For the Cévennes case, the control shows good agreement with the observations. The precipitation maxima are correctly simulated over the Cévennes crest line. Even though discrepancies exist on local intensities, especially over the western Hérault; the overall precipitation pattern, anchored to the orography, is well captured.
Keeping in mind the key role of orographic lifting for such episodes, we anticipate limited sensitivity to realistic perturbations within the microphysical scheme. Furthermore, this type of situation, dominated by a larger scale system which strongly controls the southerly low-level jet towards the impacted area, is known to be fairly predictable (Romero et al., 2005; Hohenegger et al., 2006). In contrast, the control experiment for the Gard-Hérault case appears much less skillful. The highest precipitation core is found above the Rhone valley as in the observations but occurs $60 \mathrm{~km}$ further north than observed. The 15:00 UTC AROME analysis (not shown) reveals that, in response to the convective system, a significant cold pool developed over the lower Rhône valley. As shown by Ducrocq et al. (2008), for a very similar event, the cold pool may act as a virtual topographical feature and force the moist and conditionally unstable air to rise. We therefore hypothesize that this case may be fairly sensitive to the microphysical perturbations which will impact the cold pool either directly (e.g. through evaporation) or indirectly (e.g. through hydrometeor modifications), as shown by various past studies (e.g. Van Weverberg et al., 2011; Gilmore et al., 2004).

The time evolution of the spatially averaged hourly rainfall is shown in Fig. 5. For a direct comparison with observations, the model precipitation was computed at rain gauge sites and averaged over the sub-domain shown Fig. 1. For the Gard-Hérault case (Fig. 5a), the agreement with the observations is fairly poor in the morning while deep convection is weakly developed. The intensification of the event is well seen by the simulation but is underestimated and delayed by 2 or $3 \mathrm{~h}$. This further evidences the model error regarding the onset of the MCS. Besides the already mentioned location 

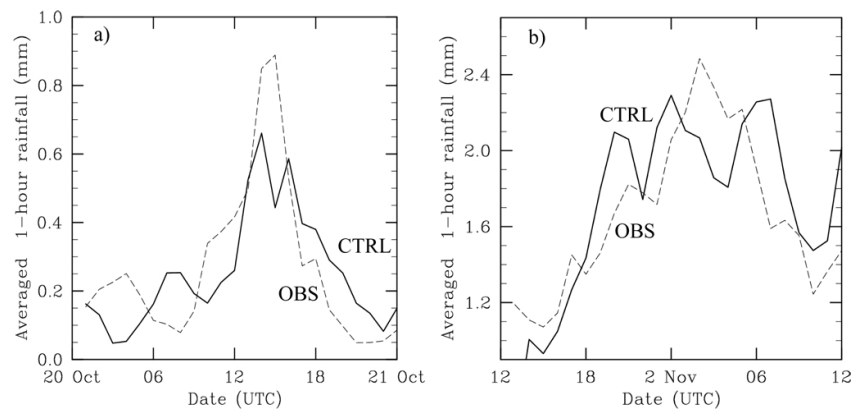

Fig. 5. Comparison of reference experiments (CTRL, bold line) and gauge observation (OBS, dashed line) for (a) the Gard-Hérault case and (b) the Cévennes case. 1-h rainfall at gauge sites, averaged over the box drawn on Fig. 1.

error, the simulated MCS occurred later than observed and did not reach the correct intensity. However, deep convection simultaneously declines in the simulation and observation by 17:00 UTC. Remaining precipitation until the end of the event is due to persistent orographic precipitation over the Cévennes ridge while the low-level flow is still oriented northward. For the Cévennes case (Fig. 5b), the time evolution exhibits weak amplitude errors especially during the most intense stage, but the general characteristics of the onset and decay stages are well reproduced. This confirms the good skill of the simulation, as it matches the observations well both in time and space.

\subsection{Ensemble experiments}

Due to the poor skill of the deterministic forecast, perturbed experiments of the Gard-Hérault case will be treated first. Figure 6 shows the $24 \mathrm{~h}$ accumulated precipitation for all perturbed members of the three ensembles, E1, E2 and E3. One overall observation that can be made is that sensitivity is noticeable at small scale in location and intensity, underlining the role of microphysical processes in controlling organisation and life time of the convective cells. The location of the most intense precipitation core varies over distances greater than $50 \mathrm{~km}$, which could have consequences for hydrological prediction. However, all experiments roughly exhibit the same spatial envelope with a precipitation band aligned along the Cévennes range and an eastward extension more or less developed over the mid-Rhône valley. None of the ensemble members is able to locate the strong convective precipitation over the southern Gard where it really occurred.

The E4 ensemble is identical to E3 but was run for the Cévennes case. The corresponding results are shown in Fig. 7. There is very little variability between the different members. The intense precipitation core remains nearly unchanged both in intensity and location. The more visible discrepancies are found for moderate precipitation over the southwestern Massif Central and in the vicinity of the coast.
To better assess the relative spread of the different ensembles, Fig. 8 shows the time evolution of the spatially averaged instantaneous precipitation rate and the accumulated precipitation. Besides the very first peak associated with model spin up, each member exhibits two main peaks in the precipitation rate. The first one to be considered occurs by 07:00 UTC, and is related to early convective cells developing over the Cévennes mountains. Then, the precipitation intensity slightly declines until 09:00 UTC before increasing again to reach its peak in the mid-afternoon in response to the MCS development.

When the perturbations are applied to the raindrop spectrum (E1), the sensitivity is fairly weak in the morning and moderate during the afternoon (Fig. 8a). The raindrop size spectrum is well known to regulate efficiency of many microphysical processes, including mixed phase processes. It is therefore not surprising to notice the non-linear response to graduated changes of the intercept $N_{\text {or }}$ (Van Weverberg et al., 2011). It is clear that raindrop size spectrum significantly impacts at least the deepest convective cells for this case. The comparatively equal sensitivity to evaporation (E2, Fig. 8c) may be surprising knowing its key role in the development of mesoscale convective organisations. It may be argued that these experiments only simulate weakly organised cells that never reach the stage at which an increase or decrease of the cold pool could significantly modify the dynamics of the storm. The third ensemble (E3, Fig. 8e) with multi-process perturbations shows noticeable bifurcations in the timing of the precipitation peak and tends to exhibit more sensitivity during the afternoon stage. It is also interesting to notice that the sensitivity remains weak during the onset, whereas perturbations applied on warm rain initiation processes are consequent. All these results indicate that, for this case, storm details become decisive on the fate of the event but only after a threshold of convection is reached. The accumulated precipitation exhibits only weak variations for E1 and E2 (Fig. 8b and d), whereas for E3 (Fig. 8f) these variations are more substantial and can reach $20 \%$ of the total observed amount.

In contrast a much weaker sensitivity is obtained for the Cévennes case (E4, Fig. 9). Even after $24 \mathrm{~h}$ of the simulation, the members hardly show any spread. This result should not be considered as a general characteristic of orographic precipitation with respect to their sensitivity to cloud physics parameterisations. In particular, several studies have shown the importance of snow parameters on the location of precipitation for a flow directed toward a mountain barrier (e.g. Colle et al., 1999; Serafin and Ferretti, 2007). In the present case, sensitivity experiments (not shown) with perturbed snow parameters did not indicate a larger spread than the one obtained in E4. It is therefore more likely that the contrasted results obtained between E3 and E4 are more linked to the intrinsic predictability of the two situations rather than to their orographic versus non-orographic character. 




Fig. 6. 24-h accumulated precipitation computed for the Gard-Hérault case. The E1, E2, E3 and E5 perturbed ensemble members are displayed from top to bottom. The E1 members are ordered with increasing $N_{\text {or }}$. For the E5 members, the location (A, B, C, and D as shown in Fig. 11) and sign ( \pm ) of the perturbation are indicated in parenthesis. See Fig. $2 \mathrm{~d}$ for the reference run.

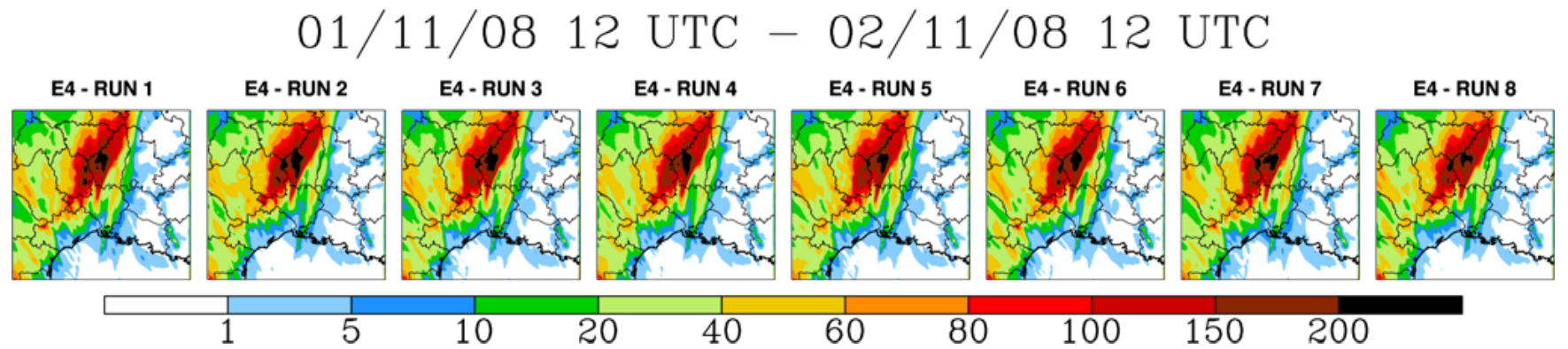

Fig. 7. Same as Fig. 6 but for the Cévennes case and the E4 ensemble. See Fig. 3d. for the reference run.

\subsection{Ensemble statistics}

The spatial distribution of the 24-h rainfall ensemble mean and standard deviation of the four ensembles are shown in Fig. 10. For the Gard-Hérault ensembles, the three ensemble means exhibit roughly the same precipitating envelope. Small scale variability among members explains the smoothing of highest rainfall over the northern Gard and southern Ardèche (see Fig. 1 for geographical location). Even though discrepancies exist, especially over southeastern Ardèche, no ensemble mean appears to be better than the other. For the three ensembles, the maximum of spread, as shown by the standard deviation from the ensemble mean, is located eastward of the precipitation maximum. This indicates that the microphysical perturbations essentially affect the MCS eastward extension and propagation across the Rhone valley but have less impact on its initial development at the Cévennes foothills. Among the three ensembles, E3 consistently presents the largest spread, with the conclusions deduced from the time evolutions shown in Fig. 8. In particular, 
E1



E2

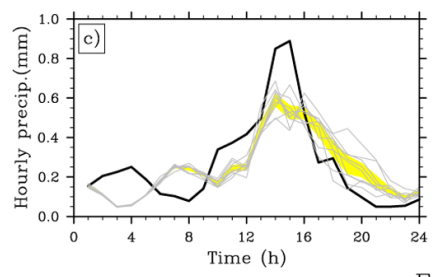

E3

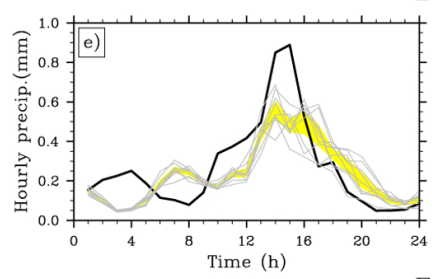

E5


Fig. 8. Time evolution of the spatially averaged hourly-precipitation rate (left) and accumulated precipitation (right) for the ensembles E1, E2, E3, and E5 (Gard-Hérault case). The ensemble members are shown in grey and the observations in black. Yellow shading corresponds to the standard deviation from the ensemble mean.

the larger spread in the northern plain of the Gard may be a clue about sensitivity of the event to displace southward. In contrast and in spite of much intense precipitation, the Cévennes case (E4) shows a much smaller spread with standard deviation maximum hardly reaching $20 \mathrm{~mm}$ as compared to the $60 \mathrm{~mm}$ of the $\mathrm{E} 3$ ensemble.

A classical way to assess a group of forecasts is to plot a Taylor diagram (Taylor, 2001), which maps the normalised standard deviation as a function of the correlation to observations. This representation also allows the unbiased normalised root mean square error (rmse) to be read graphically as the distance between the state point and the reference point (defined by normalised standard deviation and correlation equal to 1). A Taylor diagram for each of the 4 ensembles is displayed on the rightmost column of Fig. 10. A first remark to be made is the general poor skill of the Gard-Hérault simulations. Whatever ensemble is considered, the correlations remain on the order of 0.2 as opposed to 0.75 for the Cévennes simulations. The impact of the perturbations is mainly seen



Fig. 9. As Fig. 8 but for the ensemble E4 (Cévennes case).

on the standard deviation and the rmse. These plots reflect the fact that not one of the members is able to correct the spatial location error. The results obtained for the Cévennes case show a different behaviour. All members have a fairly high correlation with the observations but show a very weak sensitivity to the microphysical perturbations. In other words, the microphysical perturbations lead to moderate spread for the Gard-Hérault case for which the predictability is weak, whereas they appear to have nearly no impact for the much more predictable Cévennes case.

\section{Additional experiments}

The results obtained for the two events confirmed their distinct level of predictability. The Cévennes case is well captured with good skill scores and is fairly robust to perturbations. On the other hand, the systematic location error observed for the Gard-Hérault case dramatically affects the scores and the situation appears more sensitive to perturbations of the microphysics, although none of the ensemble members are able to provide a good forecast. It is worth noting that the weak predictability of the Gard-Hérault event was further confirmed by running an additional experiment initialized and forced with ECMWF analyses (instead of AROME analyses), and by reproducing both experiments (i.e. AROME and ECMWF based-experiments) over a double-sized domain more extended towards the northwest. Whereas the sensitivity to domain size was found to be fairly limited with both sets of analyses, the ECMWF-driven experiments appeared even less skilful than their AROME counterparts as they failed to develop any MCS over the plain and only produced moderate precipitation along the Cévennes crest (results not shown).

In order to discriminate more accurately the role of microphysical uncertainty upon predictability, further AROMEbased experiments were carried out for the Gard-Hérault case. One was to compare the propagation of microphysical perturbations with that from initial perturbations, while the other was to investigate the sensitivity to microphysics in an ensemble starting from a later analysis. In addition, the impact of the horizontal resolution was also examined. 

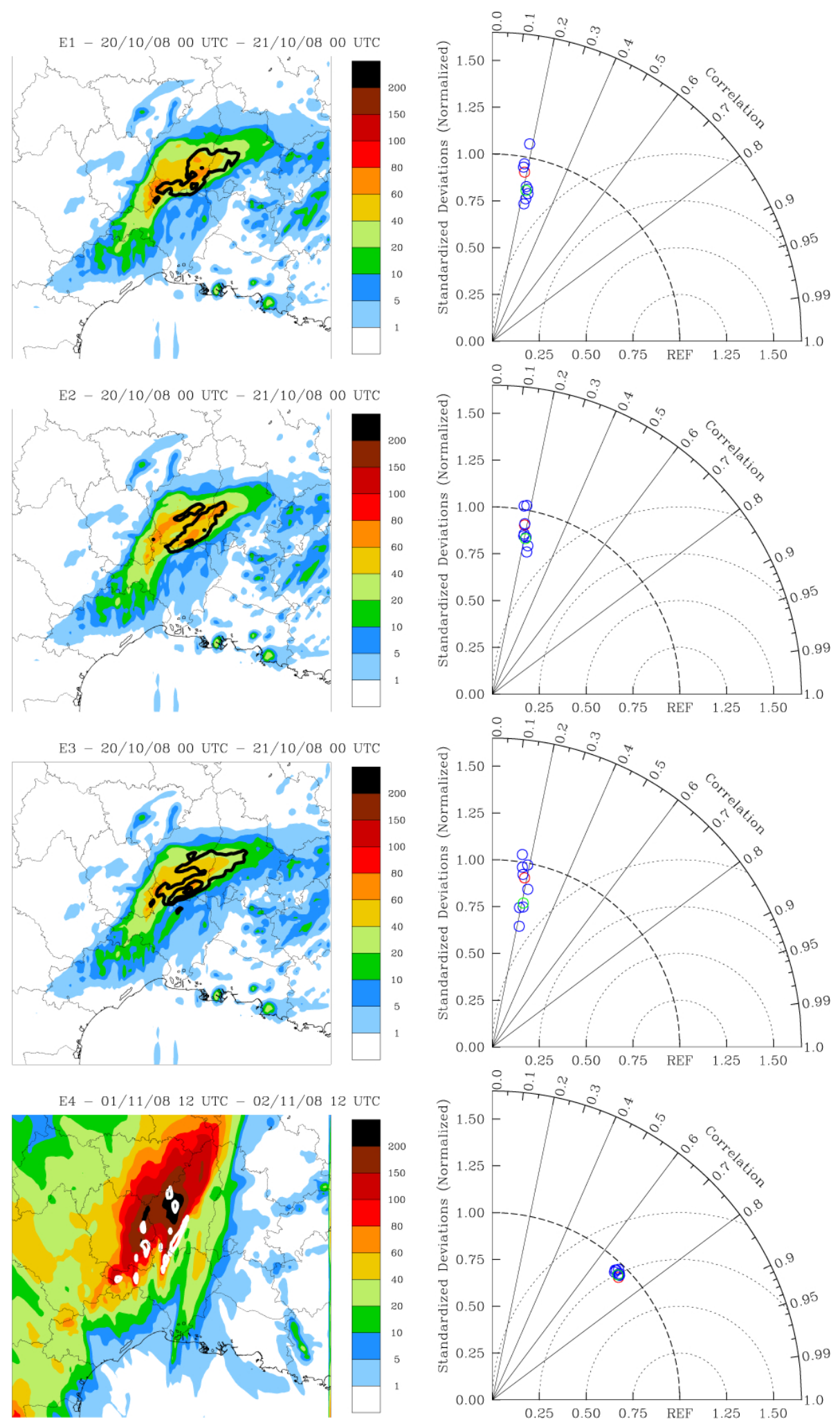

Fig. 10. 24-h accumulated precipitation ensemble statistics for E1, E2, E3 (Gard-Hérault case) and E4 (Cévennes case). Standard deviation (contour every $20 \mathrm{~mm}$ starting at $20 \mathrm{~mm}$ ) superimposed on the ensemble mean (left) and Taylor diagrams (right). On the Taylor diagrams, individual members appear in blue, the reference run in red, and the ensemble mean in green. 


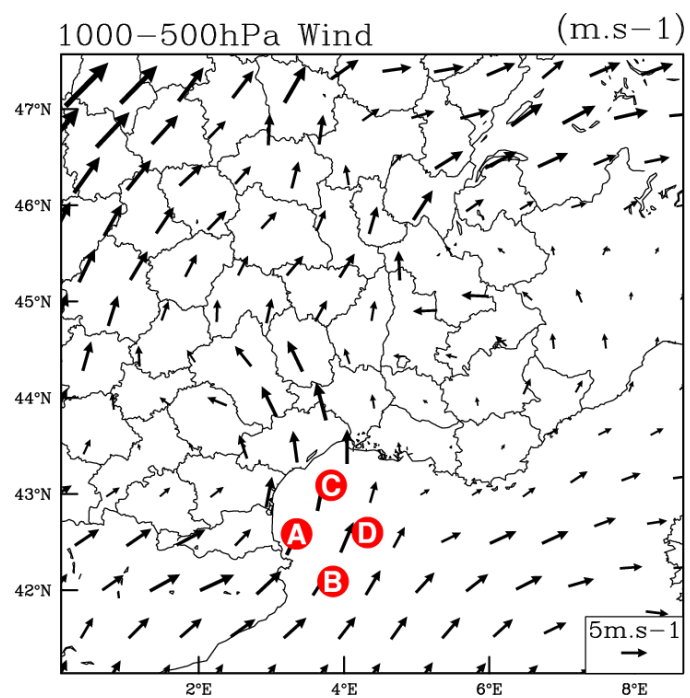

Fig. 11. Location of the centre of gaussian perturbations (red circles) for the E5 ensemble (Gard-Hérault case). Arrows show the $1000-500 \mathrm{hPa}$ vertically-averaged wind at 00:00 UTC, 20 October.

\subsection{Perturbed initial conditions}

To investigate in a simple way how initial condition uncertainties could propagate, a set of regularly-spaced Gaussian perturbations was introduced in the 00:00 UTC analysis, upwind of the relief, over the northwestern Mediterranean. Each perturbation was applied both on the temperature and the water vapour mixing ratio. Spatial extension of the perturbation was ruled by a Gaussian function with vertical and horizontal radii of $4000 \mathrm{~m}$ and $100 \mathrm{~km}$, respectively. The location of the perturbations was chosen as a function of the vertically averaged low-level flow, so that the perturbations would be advected towards the Gard and Hérault, where convection actually developed the most. The perturbations were applied at the four locations reported in Fig. 11 and were characterised by amplitudes equal to $\pm 1\left(\mathrm{~K}\right.$ or $\left.\mathrm{g} \mathrm{kg}^{-1}\right)$. Opposite signs of the perturbations allow an assessment, as to what extent the model response is linear or not, to be performed. This new ensemble (E5) also includes 9 members, the reference simulation and 8 symmetric perturbed simulations.

Figure 6 (last row) shows the $24 \mathrm{~h}$ accumulated precipitation for all the perturbed members. As expected, positive perturbations (increased moisture and temperature) favour the development of deep convection over the sea, but no experiment succeeds in simulating a MCS located near the coast. Nevertheless, large discrepancies occur regarding both the intensity and location of the event, stressing its high sensitivity to small perturbations in the initial conditions.

The time evolution of the spatially averaged hourly precipitation is plotted on Fig. 8g. In the morning the model response exhibits strong correlation between the low-level thermodynamic forcing and the onset of precipitation. The different members divide into two groups, according to the sign of the initial perturbation with the control scenario at the intermediate position. As expected positive perturbations are associated with a stronger precipitation rate, and negative perturbations with weaker ones. Later on, when deep convection takes place, this correlation disappears. These results further illustrate the role of diabatic processes in quickly restricting predictability (Hohenegger et al., 2006). Figure 8h shows the time evolution of the accumulated precipitation. After $24 \mathrm{~h}$, the spread between the different members corresponds to $35 \%$ of the observed value. Comparing Fig. $8 \mathrm{f}$ and $8 \mathrm{~h}$, it is interesting to note that initial condition perturbations introduce a larger spread in the accumulated precipitation $(35 \%$ versus $20 \%$ ) but that most of the difference occurs in the morning hours. In other words, the perturbations of the initial state induce more spread in the first $12 \mathrm{~h}$ of the simulation but similar spread in the afternoon.

As stressed by Hohenegger et al. (2006), the ensemble spread might be better assessed by computing temperature spread instead of precipitation spread which is by definition restricted to precipitating areas. The temperature spread was computed as in Hohenegger et al. (2006) for the lower troposphere (from ground to $500 \mathrm{hPa}$ ) and for the 12:00 UTC model results. Figure 12 compares the temperature spreads obtained for the E3 and E5 ensembles. In both cases, maximum spread is located over the same region, i.e. the slope of Cévennes range. This illustrates that information about the location of the initial perturbations was nearly lost after deep convection had taken place. These results are quite consistent with those of Hohenegger et al. (2006) for Alpine heavy precipitation events. However, it can be noted that perturbations applied on the initial state seem to induce a larger spread both on precipitation and temperature than perturbations applied to the cloud physics parameterisation. Thus, it is unlikely that a microphysical perturbation-based ensemble alone will be sufficient to sample actual uncertainties.

To further assess the relative behaviours of the various ensembles, Relative Operating Characteristic (ROC) curves were computed. For a given precipitation threshold, the ROC curve represents the hit rate (HIT $=a /(a+c)$ ) as a function of the false alarm rate $(\mathrm{FAR}=b /(b+d))$ where $a, b, c$, and $d$ designate the number of events, both observed and forecasted, not observed but forecasted, observed but not forecasted, and neither observed nor forecasted, respectively. The area below the ROC curve indicates the ability of the ensemble to discriminate precipitating events which are below the threshold from those which are above the threshold. An area of 0.5 indicates no discrimination, whereas an area above 0.7 is considered as useful (Buizza et al., 1999a). The ROC curves have been computed for the different Gard-Hérault ensembles and Fig. 13 represents the area under the ROC curve of the four ensembles (E1, E2, E3 and E5) as a function of the precipitation threshold. On this figure the dashed-line refers to the control experiment. In the control case, the area 

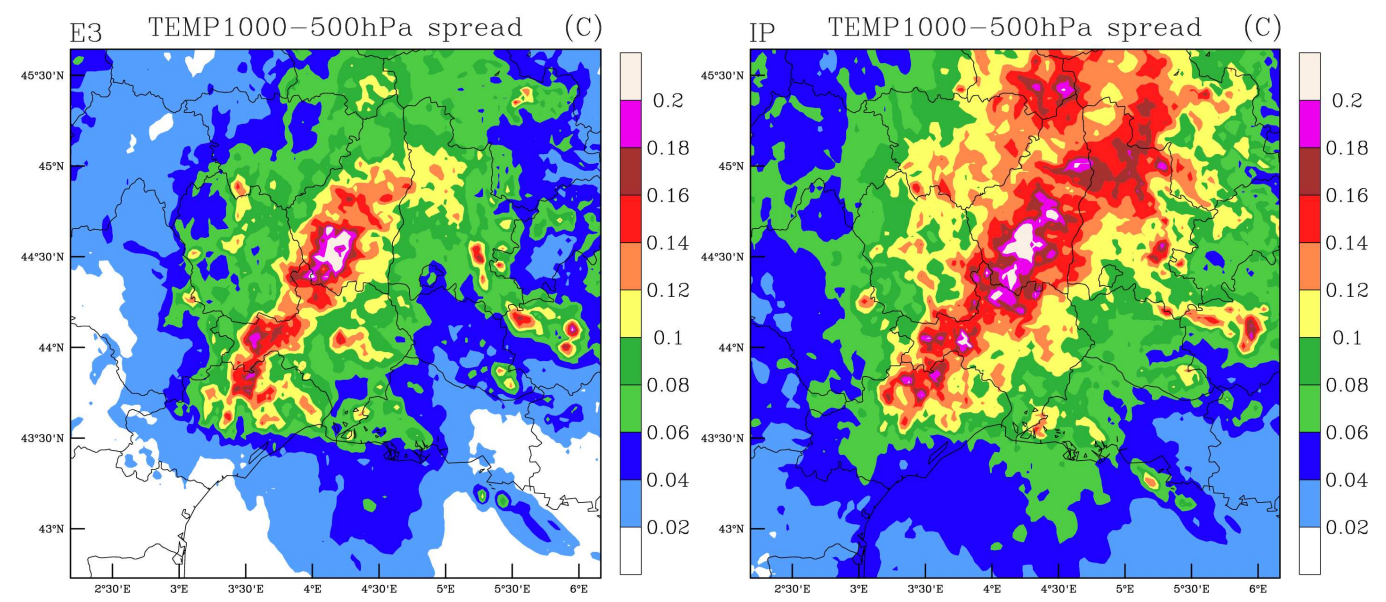

Fig. 12. Comparison of the 12:00 UTC, 20 October temperature spread for the Gard-Hérault case between the microphysical perturbation ensemble E3 (left) and initial perturbation ensemble E5 (right).

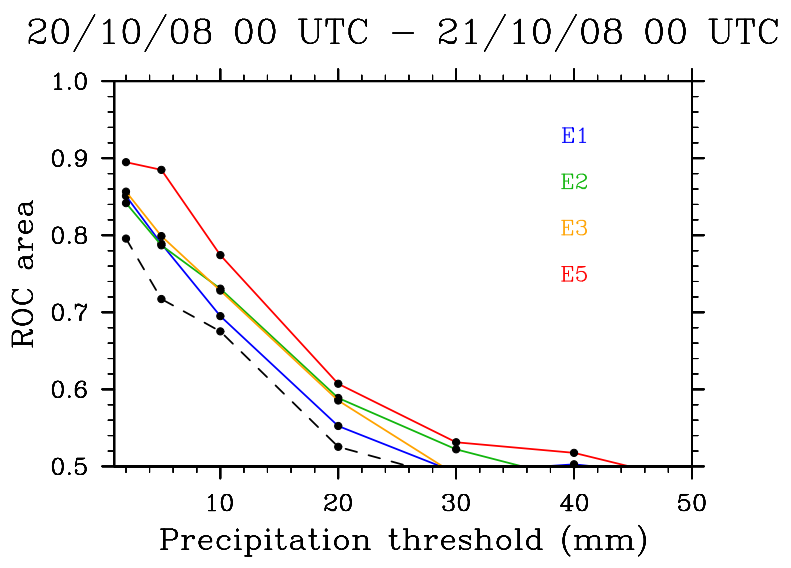

Fig. 13. Area under the ROC curve as a function of the precipitation threshold obtained for the $24 \mathrm{~h}$ precipitation of the E1, E2, E3, and E5 ensembles (Gard-Hérault case). The dotted line corresponds to the deterministic forecast.

below the ROC curve is built from a single point defined from the hit and false alarm rates, whereas for the ensembles the curve is built from hit and false alarm rate probabilities sampled from 0 to 1 with a $1 / 9$ increment (see Schwartz et al., 2010 for a more complete description of the use of ROC curves for probabilistic forecasts). From these curves, it can be seen that E5 clearly outperforms the other ensembles, E2 and E3 give roughly the same results, whereas E1 shows only a slight improvement compared to the deterministic forecast. However, all four ensembles provide added value to the deterministic forecast almost up to the $30 \mathrm{~mm}$ threshold. These results further indicate that microphysical errors might have less impact than initial condition errors but are not negligible and should, in addition, probably be considered in the design of an ensemble forecasting strategy suited for the convective scale.

\subsection{Later initial time}

The question arises whether the poor skill of the GardHérault simulations (obtained whatever perturbations are applied to the microphysics or in the local initial conditions) could be more related to poor synoptic initial conditions than model errors or local initial condition errors. This hypothesis is further supported by the fact that previous studies of this case (Ardilouze, 2009) have shown much better results for the deterministic forecast when the model was initialised at 06:00 UTC. Therefore, an E3-analog ensemble was reproduced starting from the 06:00 UTC analysis. It will be referred to as E6. Lead time of the simulations is then reduced to $18 \mathrm{~h}$ but comparison between 24 -h rainfall and 18-h rainfall is still possible because the actual MCS occurred within the last $18 \mathrm{~h}$.

Figure 14 (top row) shows the $18 \mathrm{~h}$ accumulated precipitation for all E6 perturbed members. It is clear that a substantial improvement is achieved. For all members, the high precipitation pattern is displaced southward and moved from the southern Ardèche to the northern Gard. This tends to indicate that the 00:00 UTC ARPEGE global analysis (from which derives the large-scale information of the AROME analysis) could have missed important features for the onset and maintenance of convection over the plains.

The time evolution of the spatially averaged hourly precipitation is plotted on Fig. 15a. In this experiment the MCS onset is much better forecast. The peak of convection is anticipated by 2 to $3 \mathrm{~h}$ but the strong underestimation has disappeared. As for the experiment starting at 00:00 UTC, the spread between the members is mainly seen in the decaying phase. The accumulated precipitation amount is close to the 


\section{0/10/08 06 UTC - 21/10/08 00 UTC}

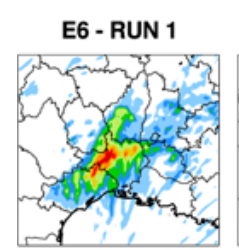

E7 - RUN 1
E6 - RUN 2

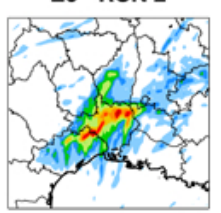

E7 - RUN 2

E6 - RUN 3

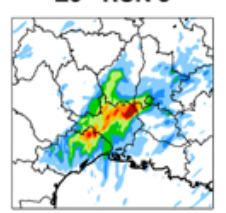

E7 - RUN 3

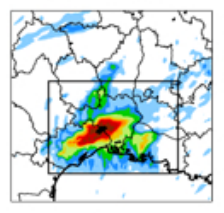

10

\section{E6 - RUN 4}

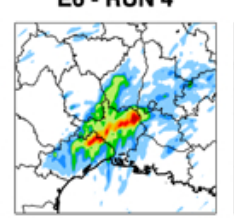

E7 - RUN 4

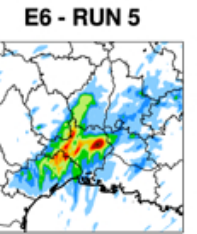

E7 - RUN 5
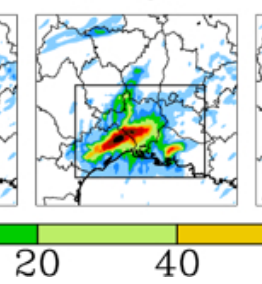

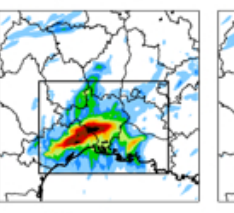

$60 \quad 80$
E6 - RUN 6

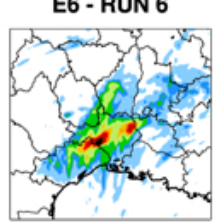

E7 - RUN 6

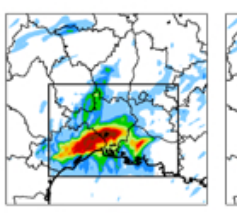

100
E6 - RUN 7

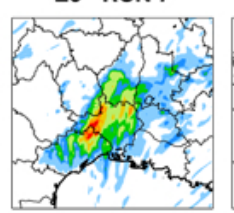

E7 - RUN 7

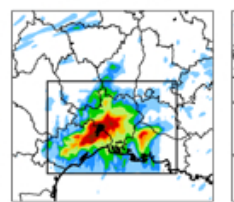

150
E6 - RUN 8

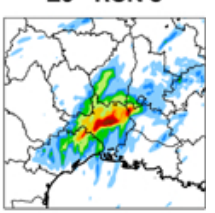

E7 - RUN 8

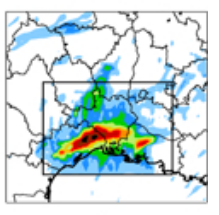

Fig. 14. $18 \mathrm{~h}$ accumulated precipitation computed for the Gard-Hérault case for the E6 (top) and E7 (bottom) ensembles. The rectangle indicates the location of the inner computational domain used in the E7 ensemble.

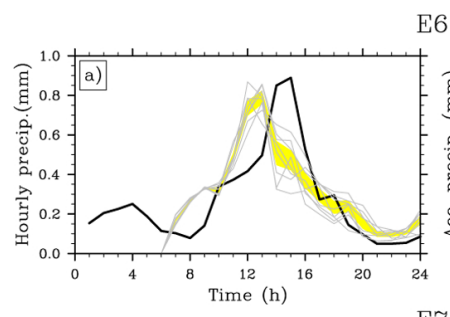

E6

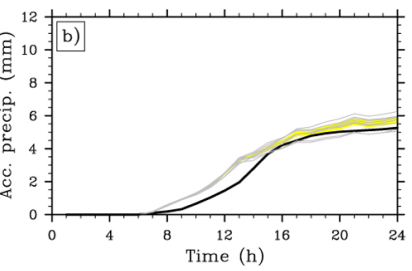

E7


Fig. 15. As in Fig.8 but for the ensembles E6 and E7.

observations and show little variation between the members (Fig. 15b).

Maps of the ensemble mean and standard deviation for this experiment are plotted on Fig. 16 (top row). Both maxima are shifted southward and are now located over the Gard department. Despite a larger value for the mean, the spread maximum did not increase dramatically $(80 \mathrm{~mm}$ as compared to the $60 \mathrm{~mm}$ of E3). As opposed to the former ensembles, the area of large spread is now co-located with the area of strong precipitation. The Taylor diagram indicates that the correlations globally improved. They are of the order of 0.3 as compared to 0.2 in E3. As for E3, the perturbations have more impact on the standard deviation and rmse than on the correlations, indicating that none of the members induce a strong displacement of the precipitation core. However, the spread between the different members as reflected by the Taylor diagram appears more significant in E6 than in E3.

\subsection{Later initial time and increased resolution}

In a final experiment, the horizontal resolution was increased to $500 \mathrm{~m}$. This was achieved by running the model on two interactively 2-way nested domains (Stein et al., 2000) with the inner domain centred over the Gard department. In this new ensemble referred to as E7, perturbations on three microphysical tendencies were applied on both domains. As for E6, the E7 simulations started at 06:00 UTC and were run for $18 \mathrm{~h}$. To avoid comparing precipitation fields of different resolutions (and the double penalty issues associated with an increase in resolution), the precipitation analysis was performed using the coarse grid results which, thanks to the 2-way nesting, could be considered as an upscaled version of the fine grid results.

Figure 14 shows the $18 \mathrm{~h}$ accumulated precipitation for all E7 perturbed members. Globally, the results are much better and now give the right location for the precipitation core. The precipitation maxima are also significantly higher and reach the observed amount. This clearly indicates that a good forecast of this event requires not only good initial conditions but also a better spatial resolution. As for the previous ensembles, the location of the precipitation maximum does not vary much between the members. The impact of the perturbations is more seen on the precipitation pattern, which is more or less widespread (especially northwards) depending on the members.

The time evolution of the spatially averaged precipitation rate (Fig. 15c) shows a more gradual increase during the MCS onset, which is in better agreement with observations but as in E6 the precipitation peak still occurs two hours too early. However, it can be noticed that the different members start to diverge earlier and that significant spread is still present at the end of the simulation. 

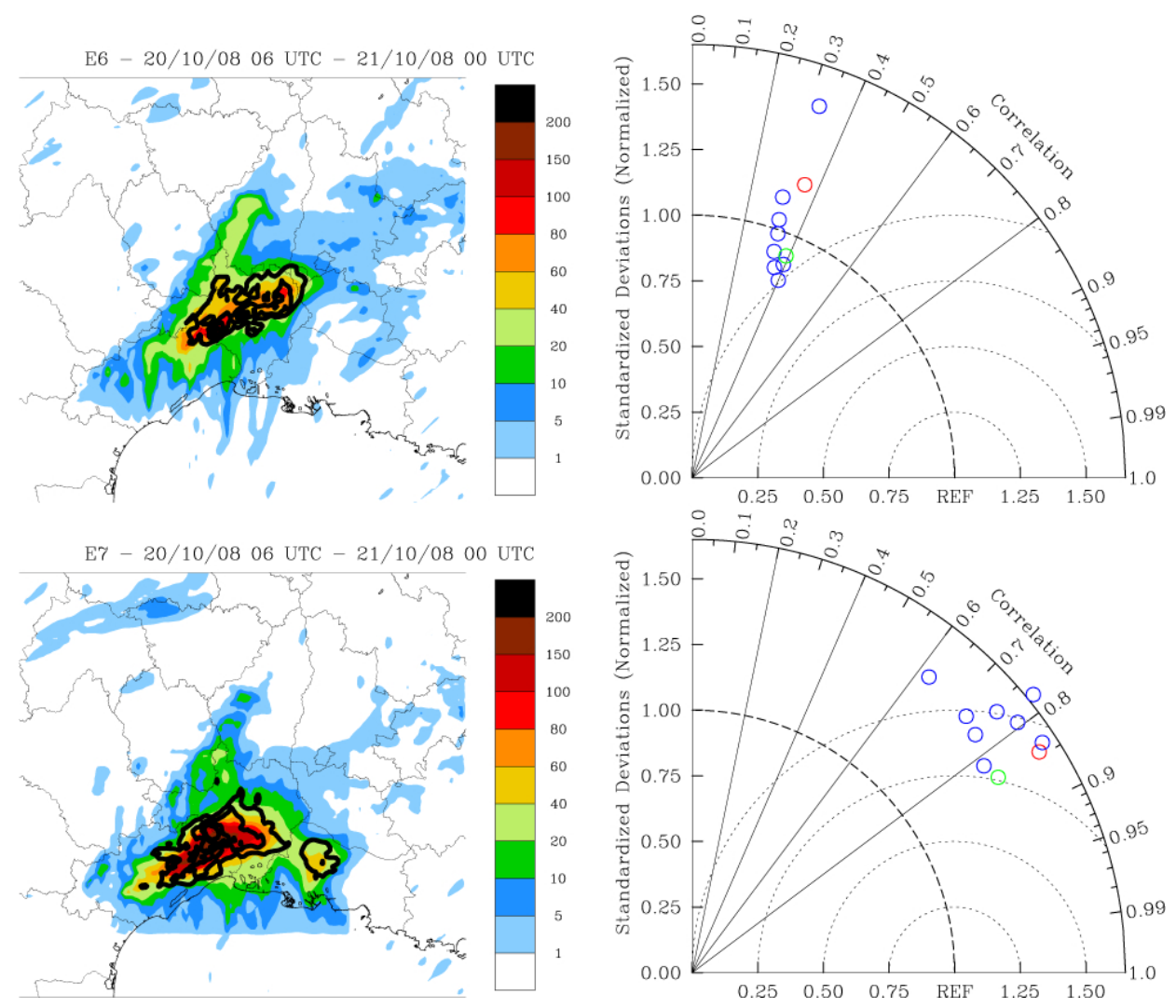

Fig. 16. As Fig. 10 but for the 18-h accumulated precipitation of the E6 and E7 ensembles (Gard-Hérault case).

The ensemble mean and standard deviation are shown in Fig. 16. The maximum spread is still co-located with the maximum of the precipitation. Compared to E6, the area of large spread is enlarged and its maximum value exceeds $80 \mathrm{~mm}$. The improvement provided by E7 is clearly seen on the Taylor diagram. The rmse variation range is about the same as in E6 but the correlations vary from 0.6 to 0.85 (compared to 0.2 to 0.3 for E6). From these figures, it seems that as the resolution is increased, the microphysical perturbations are more efficient in modifying the precipitation pattern.

To better assess the relative value of the three microphysical perturbation-based ensembles, Fig. 17 compares the area under the ROC curves obtained for E3, E6, and E7, and for the precipitation accumulated from 06:00 UTC to 24:00 UTC. This figure evidences a clear improvement from E3 to E6 and further improvement from E6 to E7. When the simulations start later (E6), the ROC area exceeds 0.5 up until the $50 \mathrm{~mm}$ threshold, compared to only $20 \mathrm{~mm}$ for E3. The improvement obtained with both later initialisation and increased resolution is even more remarkable with ROC area values exceeding 0.85 for all the thresholds. As in Fig. 13, the results of each corresponding deterministic forecasts are reported on the figure. They indicate that each ensemble provides valuable information when it is compared to its respective deterministic forecast. However, it can be noted that the

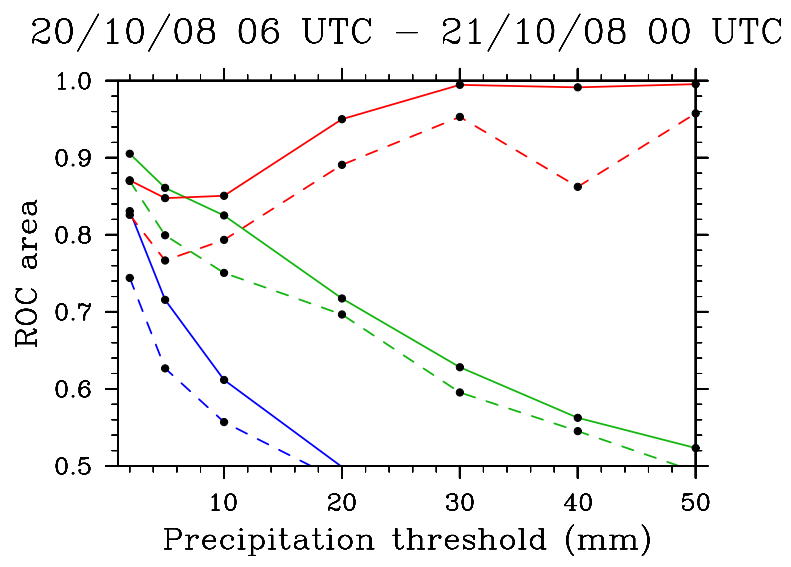

Fig. 17. Area under the ROC curve as a function of precipitation threshold obtained for the $18 \mathrm{~h}$ accumulated precipitation. Comparison of the E3 (blue), E6 (green) and E7 (red) ensembles. The dotted lines correspond to the deterministic forecasts.

added value (as estimated from the departure of the ensemble curve to its corresponding deterministic forecast curve) seems to be superior when the resolution is increased. 


\section{Conclusion and discussion}

In autumn, southeastern France is often affected by heavy precipitation events which may result in damaging flashfloods. These events usually hit the Cévennes mountainous area when an upper-level trough directs a warm and moist flow from the Mediterranean towards the topography. Alternatively, these events can also result from a quasi stationary mesoscale convective complex which develops over the Rhone valley. These two types of events exhibit a contrasting level of predictability, i.e. the former being usually better forecast than the latter. The 20 October and 1 November 2010 can be considered as archetypes of these two situations.

Control experiments performed with the Meso-NH model run with a $2.5 \mathrm{~km}$ resolution illustrate these predictability issues. The deterministic forecast of the November case (Cévennes) is found to be much more skilful than the one of the October case (Gard-Hérault plain). For this latter case, additional experiments show better results for a simulation starting $6 \mathrm{~h}$ later and further improvement when the resolution is increased to $500 \mathrm{~m}$.

These two situations have been used to investigate the sensitivity of the model to cloud physics parameterisation uncertainties. Three 9-member ensembles were constructed. In the first one, the rain distribution intercept parameter was varied within its range of allowed values. In the second one, random perturbations were applied to the rain evaporation rate, whereas in the third one random perturbations were simultaneously applied to the cloud autoconversion, rain accretion, and rain evaporation rates.

Results were assessed by comparing the time and space distribution of the observed and forecast precipitation. For the Gard-Hérault case, it was shown that none of the ensembles were able to drastically improve the skill of the forecast. The location of the most intense precipitation core was found to vary over distances greater than $50 \mathrm{~km}$ but remained located too far north with the intensity of the event also underestimated by all members. Taylor diagrams, which synthesise different statistical parameters reveal that the microphysical perturbations did induce some spread in the results but much more in the root mean square error than in the correlation coefficient, indicating that the microphysical perturbations were more efficient in modulating the rainfall intensities than in altering their localization. Among the three ensembles, the multi-process perturbation ensemble was found to yield the largest spread for most parameters, in particular for the spatially averaged accumulated precipitation and the standard deviation from the ensemble mean of the accumulated precipitation. In contrast, the results of the Cévennes case exhibited almost no sensitivity to the microphysical perturbations. These results clearly show that the usefulness of an ensemble prediction system based upon microphysical perturbations is case dependent as suggested by Stensrud et al. (2000).

For the Gard-Hérault case, the perturbed microphysics ensemble was compared with an upstream perturbed initial condition ensemble. This latter ensemble was found to induce a larger spread than any of the ensembles with perturbed microphysics. These results indicate that cloud physics parameterisation errors may have less impact than initial condition errors. However, as shown by the Relative Operating Characteristic curves, the cloud physics parameterisation errors are not negligible and should also be considered in the design of an ensemble strategy at the convective scale.

The multi-process perturbation ensemble was reconducted for simulations starting $6 \mathrm{~h}$ later, carried out first with the same resolution and then with an increased resolution. According to the Relative Operating Characteristic curves, the added value brought by the ensemble appears to be larger when the resolution is increased. These results suggest that there is a greater potential for use of ensembles based upon perturbed microphysics at the resolution of a few hundred metres.

This study is a very preliminary investigation of the propagation of cloud physics parameterisation uncertainty at the convective scale. Our results tend to indicate that the sensitivity to cloud physics parameterisation errors is probably less important than initial condition errors but is significant enough to deserve to be taken into account. However, the methodology used to account for these parameterisation errors is questionable and many issues remain open. In this study, following past results obtained with academic tests, it was assumed that warm rain processes provide the main source of uncertainty. This point needs to be further investigated for real case studies. In particular, several studies (e.g. Gilmore et al., 2004; Van Weverberg et al., 2011; Fiori et al., 2011) have underlined a large sensitivity of supercell simulations to snow and/or graupel characteristics. The amplitude of the microphysical perturbations rises another issue. It is likely that locally the microphysical tendencies can be wrong by more than $50 \%$. Although it is now admitted than limitedsize ensembles are able to capture most of the spread (Clark et al., 2011), the small size of the ensembles presented in this work is an issue that also needs further investigation. The outlook of the work will be to refine the ensemble forecasting system planned for the HyMeX 2012 SOP which focuses so far on initial and boundary condition uncertainties (Vié et al., 2011, 2012).

Acknowledgements. This work was carried out in the framework of the MEDUP project (Grant ANR-07-VULN-06-001), funded by the "Vulnérabilité Milieux et Climat (VMC)" programme of the National Research Agency (ANR). Computer resources were allocated by Grand Equipement National de Calcul Intensif (GENCI, project 90569) and Calcul en Midi-Pyrénées (CALMIP, project P1247).

Edited by: G. Molinie

Reviewed by: two anonymous referees 


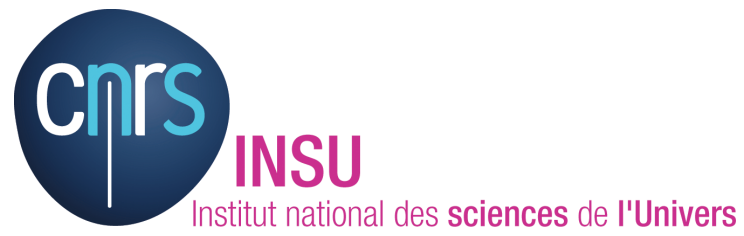

The publication of this article is financed by CNRS-INSU.

\section{References}

Ardilouze, C.: Modélisation é très haute résolution des pluies intenses méditerranéennes, Master's thesis, Université de Toulouse, 2009.

Bechtold, P., Bazile, E., Guichard, F., Mascart, P., Richard, E.: A mass flux convection scheme for regional and global models, Q. J. Roy. Meteorol. Soc., 127, 869-886, 2001.

Buizza, R., Hollingsworth, A., Lalaurette, F., and Ghelli, A.: Probabilistic predictions of precipitation using the ECMWF ensemble prediction system, Weather Forecast., 14, 168-189, 1999a.

Buizza, R., Miller, M., and Palmer, T. N.: Stochastic representation of model uncertainties in the ECMWF ensemble prediction system, Q. J. Roy. Meteorol. Soc., 125, 2887-2908, 1999 b.

Clark, A., Kain, J. S., Stensrud, D. J., Xue, M., Kong, F., Coniglio, M., Thomas, K., Wang, Y., Brewter, K., Gao, J., Wang, X., Weiss, $\mathrm{S}$., and Du, J.: Probabilistic precipitation forecast skill as a function of ensemble size and spatial scale in a convection-allowing ensemble, Mon. Weather Rev., 139, 1410-1418, 2011.

Colle, B. A., Westrick, K. J., and Mass, C. F.: Evaluation of MM5 and Eta-10 precipitation forecasts over the Pacific Northwest during the cool season, Weather Forecast., 14, 137-154, 1999.

Cuxart, J., Bougeault, P., and Redelsperger, J. L.: A turbulence scheme allowing for mesoscale and large-eddy simulations, Q. J. Roy. Meteorol. Soc., 126, 1-30, 2000.

Ducrocq, V., Nuissier, O., Ricard, D., Lebaupin, C., and Thouvenin, T.: A numerical study of three catastrophic precipitating events over southern France, II: Mesoscale triggering and stationarity factors, Q. J. Roy. Meteorol. Soc., 34, 131-145, 2008.

Fiori, E., Parodi, A., and Siccardi, F.: Uncertainty in prediction of deep moist convective processes: Turbulence parameterizations, microphysics and grid-scale effects, Atmos. Res., 100, 447-456, 2011

Franklin, C. N.: A warm rain microphysics parameterization that includes the effect of turbulence, J. Atmos. Sci., 65, 1795-1816, 2008

Fritsch, J. M. and Carbone, R. E.: Improving quantitative precipitation forecasts in the warm season: A USWRP Research and Development Strategy, B. Am. Meteorol. Soc., 85, 955-965, 2004.

Garnaud, C.: Sources d'incertitudes dans le modèle Meso-NH: le schéma microphysique, Master's thesis, Université de Toulouse, 2009.

Gilmore, M., Straka, J., and Rasmussen, E.: Precipitation uncertainty due to variations in precipitation particle parameters within a simple microphysics scheme, Mon. Weather Rev., 132, 26102627, 2004.

Grell, G. and Dévényi, D.: A generalized approach to parameterizing convection combining ensemble and data assimilation techniques, Geophys. Res. Lett., 29, 1693, doi:10.1029/2002GL015311, 2002.
Hohenegger, C. and Schär, C.: Predictability and error growth dynamics in cloud-resolving models, J. Atmos. Sci., 64, 44674478, 2007.

Hohenegger, C., Lüthi, D., and Schär, C.: Predictability mysteries in cloud-resolving models, Mon. Weather Rev., 134, 2095-2107, 2006.

Houtekamer, P., Lefaivre, L., Derome, J., Ritchie, H., and Mitchell, H.: A system simulation approach to ensemble prediction, Mon. Weather Rev., 124, 1225-1242, 1996.

Lafore, J. P., Stein, J., Asencio, N., Bougeault, P., Ducrocq, V., Duron, J., Fischer, C., Héreil, P., Mascart, P., Masson, V., Pinty, J. P., Redelsperger, J. L., Richard, E., and Vilà-Guerau de Arellano, J.: The Meso-NH Atmospheric Simulation System. Part I: adiabatic formulation and control simulations, Ann. Geophys., 16, 90-109, doi:10.1007/s00585-997-0090-6, 1998.

Lambert, D. and Argence, S.: Preliminary study of an intense rainfall episode in Corsica, 14 September 2006, Adv. Geosci., 16, 125-129, doi:10.5194/adgeo-16-125-2008, 2008.

Lorenz, E. N.: Deterministic nonperiodic flow, J. Atmos. Sci., 20, 130-141, 1963.

Lorenz, E. N.: The predictability of a flow which possesses many scales of motion, Tellus, 21, 289-307, 1969.

Miglietta, M. and Rotunno, R.: Simulations of moist nearly neutral flow over a ridge, J. Atmos. Sci., 62, 1410-1427, 2005.

Miglietta, M. and Rotunno, R.: Numerical simulations of conditionally unstable flow over a mountain ridge, J. Atmos. Sci., 66, 1865-1885, 2009.

Mlawer, E. J., Taubman, S. J., Brown, P. D., Iacono, M. J., and Clough, S. A.: Radiative transfer for inhomogeneous atmospheres: RRTM, a validated corrolated-k model for the longwave, J. Geophys. Res., 102D, 16663-16682, 1997.

Noilhan, J. and Mahfouf, J. F.: The ISBA land surface parameterisation. Global Planet Chang., 13, 145-159, 1996.

Nuissier, O., Ducrocq, V., Ricard, D., Lebeaupin, C., and Anquetin, S.: A numerical study of three catastrophic precipitating events over southern France, I: Numerical framework and synoptic ingredients, Q. J. Roy. Meteorol. Soc., 134, 111-130, 2008.

Nuissier, O., Joly, B., Ducrocq, V., Joly, A., and Arbogast, P.: A statistical downscaling to identify the large scale circulation patterns associated with heavy precipitation events over southern France, Q. J. Roy. Meteorol. Soc., 137, 1812-1827, 2011.

Palmer, T.: A nonlinear dynamical perspective on model error: A proposal for non-local stochastic-dynamic parametrization in weather and climate prediction models, Q. J. Roy. Meteorol. Soc., 127, 279-304, 2001.

Parker, M. D. and Johnson, R. H.: Organized modes of midlatitude mesoscale convective systems, Mon. Weather Rev., 128, 34133436, 2000.

Pergaud, J., Masson, V., Malardel, S., and Couvreux, F.: A parameterization of dry thermals and shallow cumuli for mesoscale numerical weather prediction, Bound. Lay. Meteorol., 132, 83-106, 2009.

Pinty, J. P. and Jabouille, P.: A mixed-phase cloud parameterization for use in a mesoscale non-hydrostatic model: simulations of a squall line and of orographic precipitations, in: Tenth AMS Cloud Physics Conference, American Meteorological Society, Everett, WA, USA, 217-220, 1998.

Romero, R., Martín, A., Homar, V., Alonso, S., and Ramis, C.: Predictability of prototype flash flood events in the Western Mediter- 
ranean under uncertainties of the precursor upper-level disturbance: the HYDROPTIMET case studies, Nat. Hazards Earth Syst. Sci., 5, 505-525, doi:10.5194/nhess-5-505-2005, 2005.

Schwartz, C., Kain, J., Weiss, S., Xue, M., Bright, D., Kong, F., Thomas, K., Levit, J., Coniglio, M., and Wandishin, M.: Toward improved convection-allowing ensemble. model physics sensitivities and optimizing probalistic guidance with small ensemble membership, Weather Forecast., 25, 263-280, 2010.

Seity, Y., Brousseau, P., Malardel, S., Hello, G., Bénard, P., Bouttier, F., Lac, C., and Masson, V.: The AROME-France convective scale operational model, Mon. Weather Rev., 139, 976-991, 2011.

Serafin, S. and Ferretti, R.: Sensitivity of a mesoscale model to microphysical parameterizations in the MAP SOP events IOP2b and IOP8, J. Appl. Meteor. Climatol., 46, 1438-1454, 2007.

Stein, J., Richard, E., Lafore, J. P., Pinty, J. P., Asencio, N., and Cosma, S.: High-resolution non-hydrostatic simulations of flashflood episodes with grid-nesting and ice-phase parameterization, Meteorol. Atmos. Phys., 72, 203-221, 2000.

Stensrud, D., Bao, J., and Warner, T.: Using initial conditions and model physics perturbations in short-range ensemble simulations of mesoscale convective systems, Mon. Weather Rev., 128, 2077-2107, 2000.
Taylor, K. E.: Summarizing multiple aspects of model performabce in a single diagram, J. Geophys. Res., 106, 7183-7192, 2001.

Van Weverberg, K., van Lipzig, N., and Delobbe, L.: The impact of size distribution assumptions in a bulk one-Moment microphysics scheme on simulated surface precipitation and storm dynamics during a low-topped supercell case in Belgium, Mon. Weather Rev., 139, 1131-1147, 2011.

Vié, B., Nuissier, O., and Ducrocq, V.: Cloud-resolving ensemble simulations of mediterranean heavy precipitating events: Uncertainty on initial conditions and lateral boundary conditions, Mon. Weather Rev., 139, 403-423, 2011.

Vié, B., Molinié, G., Nuissier, O., Vincendon, B., Ducrocq, V., Bouttier, F., and Richard, E.: Hydro-meteorological evaluation of a convection-permitting ensemble prediction system for Mediterranean heavy precipitating events, Nat. Hazards Earth Syst. Sci., 12, 2631-2645, doi:10.5194/nhess-12-2631-2012, 2012.

Walser, A.: Predictability of precipitation in a cloud-resolving model, Mon. Weather Rev., 132, 560-577, 2004. 